\title{
Antibioprophylaxy by the Surgery Staff in the Teaching Hospital Gabriel Touré in Mali
}

\author{
Bakary Tientigui Dembélé1,2, Alhassane Traoré1,2, Adégné Togo ${ }^{1,2}$, Lassana Kanté1,2, \\ Ibrahim Diakité ${ }^{2}$, Amadou Traoré ${ }^{2}$, Bourama Emmanuel Cissoko², Madiassa Konaté2, \\ Boubacar Karembé2, Yacaria Coulibaly1,2, Soumeila Keita1, Mamby Keita1,2, \\ Souleymane Diallo ${ }^{1,3}$, Gangaly Diallo ${ }^{1,2}$ \\ ${ }^{1}$ Faculty of Medicine and Odonto-Stomatology, Bamako, Mali \\ ${ }^{2}$ Department of General Surgery, CHU Gabriel Touré, Bamako, Mali \\ ${ }^{3}$ Department of Biology and Laboratory, CHU Gabriel Touré, Bamako, Mali \\ Email: btdembele@gmail.com
}

Received 17 February 2015; accepted 18 March 2015; published 19 March 2015

Copyright (C) 2015 by authors and Scientific Research Publishing Inc.

This work is licensed under the Creative Commons Attribution International License (CC BY).

http://creativecommons.org/licenses/by/4.0/

c) (i) Open Access

\section{Abstract}

This prospective survey was conducted from February to December 2014 about the use ceftriaxone (ceftriaz) for antibioprophylaxy concerning 300 patients by the surgery staff in the Gabriel Touré Teaching Hospital in Mali. The quantity of drug used was based on the weight of the patient. One dose was administrated in intravenous at the anesthesiology induction time. For more than 2 hours of intervention time, $4(1.3 \%)$ patients received a second dose. The majority of cases $(189$, $63 \%$ ) were out of emergency (emergency cases-111, 37\%). The mean age was 41.6 years (range: 3 - 95 years). The patients were classed Altmeir II 203 (67.7\%) and Altmeir I 97 (32.3\%). The NNISS score 0 concerned $101(33.6 \%)$ and NNISS 1 in $180(60 \%)$ patients. The factors of risky were anemia $(38 ; 12.7 \%)$, diabetes $(6 ; 2 \%)$, and HIV $(3 ; 1 \%)$. The mean of intervention duration was 56.8 \pm 27.5 minutes. Four cases of intervention site infection were encountered caused by Pseudomonas aeruginosa in 2 patients; Escherichia coli (1 case), and Staphylococcus aureus (1 case). Conclusion: Antibioprohylaxy is not the only way to prevent infections but it stays necessary. The respect of hygien and aseptic measures should be used to reduce the rate of intervention site infection.

\section{Keywords}

Antibioprophylaxy, Infection Risky Factors, Surgery

\section{Introduction}

Antibiotic prophylaxis is antibiotic administration before the potential bacterial contamination due to a danger-

How to cite this paper: Dembélé, B.T., Traoré, A., Togo, A., Kanté, L., Diakité, I., Traoré, A., Cissoko, B.E., Konaté, M., Karembé, B., Coulibaly, Y., Keita, S., Keita, M., Diallo, S. and Diallo, G. (2015) Antibioprophylaxy by the Surgery Staff in the Teaching Hospital Gabriel Touré in Mali. Surgical Science, 6, 138-142. http://dx.doi.org/10.4236/ss.2015.63022 
ous situation during a surgical procedure [1]. The sole fact of breaking the skin barrier suggests a risk of infection to the ill. The first job of the surgeon is asepsis, and this one may be insufficient. That is the reason why the support of an antibioprophylaxy should be questioned [2]. Many studies have been conducted to make this antibiotic indisputable today. In 1984, Vachon [3] enunciated practical methodologies of antibiotic prophylaxis.

In 1992, Classen [4] found that ever risky factors were associated with clean or clean-contaminated surgery; the incidence of postoperative infections was 3.8\% when the antibiotic was administered 2 hours before the incision, and this increased incidence when it was administered over 2 hours before the incision (4\%) or after the incision (6\%). A Nigerian study on attitudes and practical knowledge on perioperative use of antibiotics showed a confusing situation between anesthetists and surgeons [5].

Our objectives were to determine the prevalence of antibiotic prophylaxis after surgical site infection (SSI), to assess the effect of antibiotic prophylaxis on the reduction of surgical site infection, to identify the causative organisms of SSI after antibiotic, to analyze the consequences of the SSI over the duration of post-operative care of the sick, and to assess the cost of the treatment after antibiotic prophylaxis.

\section{Methods}

Our prospective study conducted over a period of 11 months from February 2014 to December 2014 included patients operated in the general surgery service and care of emergency February 2014 to December 2014 and who received ceftriaz (ceftriaxone) at the time of anesthesia induction. Patients in Class I Altemeier (clean surgery) with an infectious risk estimated by the score of 2 NNISS [6]. Patients in Class II Altemeier (clean-contaminated surgery) [6].

As we used the antibiotic ceftriaxone belonging to the beta-lactam, its half life is 7 hours. This antibiotic was chosen taking into account its spectrum of activity on causative of surgical site infection in our service. The dose was dependent on the weight of our patients; a single dose was given at the time of induction of anesthesia, a feedback was carried out for a duration of response was greater than 2 hours.

To do this we relied on previous studies in our department. These studies determined the SSI responsible germs in the service and their sensitivity to antibiotics.

Among these organisms there was Escherichia coli (29.1\%), Staphylococcus aureus (11.3\%), Pseudomonas aeruginosa (8.1\%), Citrobacter frundii (8.1\%), Klebsiella pneumoniae (8.1\%), Enterobater cloacae (8.1\%), Proteus mirabilis (3.2\%), Serratia odoriferi (3.2\%).

The dose of the antibiotic used was the weight of the patient; with an administration intravenously; this had the effect of achieving the highest tissue levels as quickly as possible, the single dose was used with a feedback in the case of higher response time to 2 hours.

The operated patients had a clinical and laboratory monitoring, the temperature was regularly taken. Asepsis was advised in bandages.

In case of fever (temperature above $38^{\circ} \mathrm{C}$ ), etiologic research was undertaken.

If parietal suppuration, a sample was taken and sent to the laboratory of CHU Gabriel Toure for bacteriological analysis and sensitivity.

\section{Results}

Indeed, we have compiled 300 cases, 111 (37\%) cases of emergency, and 189 (63\%) cold; the average age was 41.6 years, ranging from 3 to 95 years, and sex ratio of 0.8 .

The mean duration of preoperative stay was 1.3 days, with a range from 0 to 13 days. We made 4 cases of reinjections (or 1.3\%) for the duration of these interventions was over 2 hours.

The average weight of the patients was 62.3 kilograms with a range of $17-104 \mathrm{~kg}$.

Patients were classified Altmeir I in 97 (32.3\%) cases and Altmeir II in 203 (67.7\%); Score 0 NNISS was 101 (33.6\%), NNISS 1180 (60\%), NNISS 219 (6.4\%); regarding risk factors, 38 (12.7\%) of patients had a biological anemia, 6 (2\%) had diabetes, and $3(1 \%)$ had HIV, the average duration of interventions was 56.8 minutes \pm 27.5 .

We recorded $4(1.3 \%)$ cases of surgical site infection. These infections surgical site through, there were 1 diabetes, 1 case of biological anemia, 3 emergency, 2 cases score NNISS 2.

Germs found in these 4 cases of infection were Escherichia coli (1 case), Staphylococcus aureus (1 case) and Pseudomonas aeruginosa (2 cases). The average length of postoperative hospital stay of patients who presented a surgical site infection was 13 days \pm 10.3 ; and that of non-infected patients was $7.2 \pm 6.4$ hours. 


\section{Discussion}

Our SSI rate of $1.3 \%$ after antibiotic prophylaxis remains high, it is similar to that of German S [5] (P=0.49). It is statistically higher than those in developed countries: Kernodle DS; German S and Yamamoto S [7]-[9] (respectively $\mathrm{P}=0.02 ; 0.034 ; 0.036$ ) is multifactorial. SSI can be related to lack of means; the precarious facilities block; the lack of rigor in the apepsie, antiseptics because we unique. Mazaki months use hardware et al. [10] had found $2 \%$ on SSI hernia prosthesis with antibiotic prophylaxis. Our average age of 41.6 years infected patients is not different from that of uninfected patients equal to 40.2 (with $\mathrm{P}=0.73$ ). No link was found between SSI and sex in our study (with $\mathrm{P}=0.25$ ). We believe as others [11] [12] that sex is not a factor in the development of SSI. As against others consider the importance of subcutaneous fat in women as a factor that may influence the occurrence of surgical site infection [13]. Our average length uninfected patients in 1.5 days is not different from that of infected patients is 1.4 days $(\mathrm{P}=0.85)$.

It is generally accepted that preoperative hospital stay negatively influences the rate of SSI [14] [15]. Indeed, during preoperative hospitalization, and digestive microbial skin flora is modified at the 3rd and 4th day of hospitalization; Our mean operating time uninfected patients $56.8 \mathrm{mn} 04 \mathrm{~s}$ is not statistically different from that of patients infected $60 \mathrm{mn} 10 \mathrm{~s}(\mathrm{P}=0.70)$. It is generally accepted that the rate of SSI is influenced by the duration of the intervention [16] [17] difference in our series could. The lack of difference in our series could be related to the fact that in $98.6 \%$ of cases, our response time was less than 2 hours.

Our results are in the intervals of the CDC [6] when antibiotic prophylaxis is practiced, i.e. $<1 \%$ for class I and at 7\% for class II Alteimeier. No SSI was registered in class I; this result was found by other authors [18] [19] that were antibiotic prophylaxis. Statistically, our rate is lower than those of the authors who did not antibiotic prophylaxis [20] (with $\mathrm{P}=10-6$ ). For class II Alteimeier our results are statistically higher than those of the French and American series $(P=0.036$ and 0.034). Strict compliance with asepsis and antisepsis, equipment and behavioral point of view may be the cause of this difference.

As against our rate is statistically lower than for series in which antibiotic prophylaxis was not performed [20] $(\mathrm{P}=0.04)$. We are seeing an increase in SSI rates in connection with the score NNISS in our series. Like other authors [8] [18] [20] we have not recorded score of 3. For patient scores 0 and 1 we found no statistically significant difference with the literature [8] [18] [21] [22] (with P varying between 0.05 and 0.81). Against by the score 2 for our SSI rate is statistically higher than in literature [18] [20]-[22] (with P varying between 10 - 6 and 10 - 3). Score NNISS being multifactorial comparison seems difficult but it is a better indicator of risk of infection compared to the one taken Alteimeier classification. We noted a higher SSI levels in diabetics (40\%) against $1.7 \%$. The difference was significant $(\mathrm{P}=0.008)$.

In all series hyperglycemia has been recognized as a risk factor for SSI [11] [23]. Diabetes increases the rate of SSI because of the complications it causes. The vaso-occlusive disorders, immunological failure and malfunction of neutrophils [24] [25]. SSI rates in patients underwent emergency surgery was statistically different from that of patients operated cold $(\mathrm{P}=0.03)$. This could be related to the context of the emergency or the patient is not adequately prepared [26]. Other authors consider that against by the urgency has no influence on the SSI [27] [28]. In the literature [26] urgency is recognized as a risk factor SSI where it is difficult to put the patient in optimal physiological conditions before surgery.

In many studies [29]-[31], Escherichia coli was the most frequently isolated (42.9\% in our series). For other Staphylococcus aureus is the most germ found on the operative site [32]. Both in Europe [33], the USA [34] and Africa [35], Escherichia coli, Staphylococcus aureus, Proteus mirabilis, Pseudomonas aeruginosa, Klebsiella pneumoniae were the germs problem in our hospitals.

The duration of postoperative hospitalization of our infected patients has been increased significantly $(\mathrm{P}=$ 0.002.). This extension was 15 days or 2 times more than non-infected. Some authors have found as our series, an extended hospital stay of infected patients 2 to 2.5 times higher than uninfected [20] [21]. Bush according to [26], SSI increases postoperative hospital for 5 to 10 days.

\section{Conclusion}

Antibiotic prophylaxis should be integral with the strict respect of hygiene and aseptic technique in the operating room at the sterilization and in the halls of hospitalizations for an effective fight against post-operative infections. 


\section{References}

[1] Martin, C., Bantz, P. and Gouin, F. (1994) Antibioprophylaxie en milieu chirurgical. Annales de Chirurgie, 415, 310319.

[2] Detry, R., Saba, J. and Kesterns, P.J. (1990) Prévention des complications infectieuses en chirurgie digestive Résultat d'expérience de 582 cas. Annales de Chirurgie, 40, 305-334.

[3] Vachon, F. (1984) Méthodologie pratique pour l'usage rationnel de l'antibiothérapie à visée préventive. Médecine et Maladies Infectieuses, 14, 695-703. http://dx.doi.org/10.1016/S0399-077X(84)80034-7

[4] Classen, D.C., Evans, R.S., Pestotnik, S.L., et al. (1992) The Timing of Prophylactic Administration of Antibiotics and the Risk of Surgical Wound Infection. New England Journal of Medicine, 326, 281-286. http://dx.doi.org/10.1056/NEJM199201303260501

[5] Ajibade, A. and Olaitan, P.B. (2014) Knowledge, Attitude and Practice of Peroperative Antibiotic Prophylaxis among Nurse-Anesthetists in Nigeria. Nigerian Journal of Medicine, 23, 142-148.

[6] CDC Atlanta, Les infections nosocomiales (1990) Recommandations en matière d'enregistrement des infections nosocomiales. American Journal of Infection Control, 14, 1-10.

[7] Tönz, M., Schmid, P. and Kaiser, G. (2002) Antibiotic Prophylaxis for Appendectomy in Children: Critical Appraisal. World Journal of Surgery, 24, 995-998. http://dx.doi.org/10.1007/s002680010161

[8] Kernodle, D.S. (1998) Post Operative Infection and Antimicrobial Prophylaxis. American Journal of Infection Control, 27, 42-56.

[9] Yamamoto, S. (2004) A Multicenter Prospective Study for Antibiotic Prophylactic to Prevent Preoperative Infection in Digestive Surgery. Hinyokikakiyo, 50, 673-683.

[10] Mazaki, T., Mado, K., Masuda, H., et al. (2014) A Randomized Trial of Antibiotic Prophylaxis for Prevention of Surgical Site Infection after Open Mesh-Plug Hernia Repair. American Journal of Surgery, 207, 476-484. http://dx.doi.org/10.1016/j.amjsurg.2013.01.047

[11] Kitzis, M. (1991) Risques infectieux en chirurgie Antibioprophylaxie: Nouvelles stratégies 9ème congrès Français de chirurgie. La Revue du Praticien, 9, 15-21.

[12] Haley, R.W., Hooton, T.M., Culver, D.H., Stanley, R.C., Grace Emori, T., David Hardison, C., et al. (1981) Nosocomial Infection in U.S. Hospitals 1975-1976: Estimated Frequency by Selected Characteristic of Patients. American Journal of Medicine, 70, 947-959. http://dx.doi.org/10.1016/0002-9343(81)90561-1

[13] Lawer, S. (2001) Laboratorium microbiologie, Dienst Ziekenhnishygiène, laorbuklann. Pharmacy World and Science, 17, 36-40.

[14] Nooyen, S.M., Overbeek, B.P., Brutel de la Rivière, A., Storm, A.J. and Langemeyer, J.J. (1994) Prospective Randomized Comparison of Single Dose versus Multiple-Dose Cefuroxime for Prophylaxis in Coronary Artery Bypass Grafting. European Journal of Chiropractic, 13, 1033-1037.

[15] Raja’Aya, Salam, A.R., Salih, Y.A., et al. (2002) Surgical Site Infection. Annales de Chirurgie, 6, 9-17.

[16] Martin, C., Vivian, X. and Gouin, F. (1999) Pratique de l'antibioprophylaxie en chirurgie. Anesthésie-réAnimation, 12, 983-987.

[17] Wiedman, B. (1993) Résistance aux antibiotiques. Reviews of Infectious Diseases, 16-18.

[18] Lallemand, S., Thouverez, M., Bailly, P., Bertrand, X. and Talon, D. (2002) Non-Observance of Guidelines for Surgical Antimicrobial Prophylaxis and Surgical Site Infection. Pharmacy World and Science, 24, 95-99. http://dx.doi.org/10.1023/A:1016122202439

[19] Eleck, S.D. and Conen, P.E. (1957) The Virulence of Staphylococcus pyogenes for Man: A Study of the Problems of Wound Infection. British Journal of Experimental Pathology, 38, 573-586.

[20] Nguyen, D., Maceod, W.B. and Phung, D.C. (2002) Fungal Infections. New England Journal of Medicine 12, 25-34.

[21] Pishort, T., Sidiqui, A.R. and Ahmed, M. (2003) Surgical Wound Infection Surveillance in General Surgery Procedures at a Teaching Hospital. Annales de Chirurgie, 10, 91-96.

[22] Culver, D.H., Horan, T.C., Gaynes, R.P., Martone, W.J., Jarvis, W.R., Grace Emori, T., et al. (1991) Surgical Wound Infection Rates by Wound Class, Operative Procedure and Patient-Risk Index. American Journal of Medicine, 91, S152-S157. http://dx.doi.org/10.1016/0002-9343(91)90361-Z

[23] Malone, D.L., Genitt, Tracy, J.K., et al. (2002) Surgical Site Infection. Pharmacy World and Science, 24, 95-98.

[24] Dellamonica, P., Bernard, E., Maestracci, P., Berre, A., Etienne, M. and Bocquet, J.P. (1982) Facteurs discriminants du risque infectieux en chirurgie digestive réglée Essai à propos de 308 cas. Annales de Chirurgie, 36, 531-537.

[25] Maucort Boulach, D., Tauboutin, S., et al. (2002) Rev Prat Paris, 47, 204-209. 
[26] Brun-Buisson, C. and Girou, E. (2000) Les infections nosocomiales: Bilan et perspectives. Revue Médecine/Sciences, 16, 892-899. http://dx.doi.org/10.4267/10608/1753

[27] Sewonou, A., Rioux, C., Golliot, F., et al. (2000) Report on Patient Management Best Practices. Methods for Identifying Surgical Wound Infection. Annales de Chirurgie, 23, 86.

[28] Polk, H.C. and Lopez-Mayor, J.F. (1989) Postoperative Wound Infection: A Prospective Study of Determinant Factors and Prevention. Surgery, 66, 97-103.

[29] Arias, C.A., Quitero, G., Vanegas, B.E., et al. (2003) Surveillance of Surgical Site Infections: Decade of Experience at a Colombian Tertiary Care Center. World Journal of Surgery, 27, 529-533. http://dx.doi.org/10.1007/s00268-003-6786-1

[30] McCormack, J.G. and Barnes, M. (1993) Nosocomial Infection in a Developing Middle East Hospital. Médecine et Maladies Infectieuses, 7, 45-61.

[31] Chamoine, Z. (2000) Prévention des infections nosocomiales Objectifs soins. Annales de Chirurgie, 83, 20-25.

[32] Tulkens, P. and Spinervine, A. (1997) Université catholique de Louvain. Pharmacologie et Pharmacothérapie des antiinfectieux. Journal of Clinical Pharmacology, 13, 62-69.

[33] Jupeau Vessieres, A.H. and Scavizzi, M.R. (1995) Maladies Infectieuses. Encyclopédie Medico Chirurgicale, 77-83.

[34] Pryor, K.D. and Fahey, T.J. (2004) Biologic Variables Associated with Cummulus oocyte Complex Recovery Using Follicular Aspiration. American Journal of Surgery, 10, 62-69.

[35] Anagonous, S.Y., Makoutode, M. and Amassoubdji, B. (1994) Sensibilité aux antibiotiques de Escherichia coli en milieu hospitalier à propos de 1468 souches isolées au centre hospitalier et universitaire de Cotonou. Médecine d'Afrique noire, 13, 8-10. 